\title{
Capacidades governamentais municipais e desenvolvimento humano local no Brasil
}

\section{Rony Coelho}

Universidade Estadual de Campinas (Unicamp), Campinas, SP - Brasil

\section{Felipe Guth}

Banco Nacional de Desenvolvimento Econômico e Social (BNDES), Rio de Janeiro, RJ - Brasil

\section{Miguel Loureiro}

Institute of Development Studies (IDS), Brighton - Reino Unido

Este trabalho tem por objetivo analisar a relação entre capacidades governamentais municipais e desenvolvimento humano no Brasil. Para tal, construímos um quadro teórico-analítico que propõe tipos de capacidades de gestão municipal e como mensurá-las. Em seguida, recorrendo a técnicas de regressão logística, distribuição de frequências e análises geoespaciais, analisamos em que medida essas capacidades estão associadas à variação no Índice de Desenvolvimento Humano (IDH-M) em municípios com menos de 50 mil habitantes ( $85 \%$ do total). As avaliações tomam por base três diferentes áreas de políticas públicas: saúde, educação e assistência social. Os resultados sugerem que atividades de planejamento e de interação com outros atores possuem uma associação maior com o IDH-M do que adoção de fundos ou estruturas administrativas. A quantidade de conselhos participativos, de planos e consórcios tem efeito significativo e positivo.

Palavras-chave: capacidades estatais, gestão municipal, desenvolvimento humano 


\section{Capacidades estatales municipales y desarrollo humano local en Brasil}

Este documento tiene como objetivo analizar la relación entre las capacidades municipales del estado y el desarrollo humano en Brasil. Con este fin, construimos un marco teórico-analítico que propone tipos de capacidades de gestión municipal y cómo medirlas. Luego, utilizando técnicas de regresión logística, distribución de frecuencia y análisis geoespacial, analizamos en qué medida estas capacidades están asociadas con la variación en el Índice de Desarrollo Humano (IDH-M) en municipios con menos de 50 mil habitantes ( $85 \%$ del total de municipios). Las evaluaciones se basan en tres áreas políticas diferentes: salud, educación y asistencia social. Los resultados sugieren que las actividades de planificación y la interacción con otros actores tienen una mayor asociación con el IDH-M que los recursos o las estructuras administrativas. La cantidad de consejos participativos, planes y consorcios tiene un efecto significativo y positivo.

Palabras clave: capacidades estatales, gestión municipal, desarrollo humano

\section{Municipal state capacity and local human development in Brazil}

This paper analyses the relationship between municipal state capacities and human development in Brazil. For that, we built a framework that indicates types of municipal management capacities and how to measure them. Using logistic regression, frequency distribution, and geospatial analysis, we analyse the extent these capacities are associated with the variation in Human Development Index (HDI-M) in municipalities with less than 50 thousand inhabitants ( $85 \%$ of all municipalities). The assessments are based on three different policy areas: health; education; and social assistance. The results suggest that planning activities and interaction with other actors have a greater association with HDI-M than resource endowment or administrative structures. The number of participatory councils, plans and consortia are statistically significant and have a positive effect.

Keywords: state capacity, local government, human development 


\section{Introdução ${ }^{1}$}

A Constituição Federal de 1988 outorgou autonomia política, administrativa e financeira aos municípios brasileiros, incumbindo-os de legislar sobre os assuntos locais, de forma suplementar e cooperativa aos demais entes federados, estados e União. Os municípios se tornaram, assim, as "unidades de governo" mais próximas aos cidadãos (SADEK, 1991), responsáveis por uma série de competências em relação às políticas sociais e ao planejamento governamental local, ainda que a execução de muitas dessas competências seja dada sob um arranjo de indução federal (ARRETCHE, 2012). Logo, cabe perguntar como as ações governamentais se dão no nível local. Ou como o poder público mobiliza e opera suas ações e mecanismos nos municípios?

Essas são perguntas que podem ser colocadas de muitas formas correlatas, e diversos caminhos podem ser tomados para respondê-las. Um deles, o que optamos por explorar neste artigo, é buscar apoio nos recentes desdobramentos das discussões sobre capacidades estatais. O que é capacidade estatal e como ela afeta o desenvolvimento econômico e social são algumas das principais perguntas colocadas desde os estudos neoinstitucionalistas pioneiros sobre o papel do Estado (CINGOLANI, 2013). Não obstante, nos últimos anos, o interesse pelo tema tem ressurgido nos debates acadêmicos internacionais (BERSCH; PRAÇA; TAYLOR, 2013) e analistas têm buscado compreender como mensurar uma "boa governança" (BERSCH; PRAÇA; TAYLOR, 2017; FUKUYAMA, 2013; HANSON; SIGMAN, 2013). Esse movimento tem influenciado a produção acadêmica brasileira (GOMIDE; PereirA; MACHAdo, 2017; AgUIAR; LIMA, 2019) que, capitaneada pelo Ipea (PIRES; GoMIDE, 2016) e pela Enap (2018a, 2018b), tem tentado avaliar empiricamente a qualidade das ações estatais no país. Grande parte dessa produção tem focado atenção no plano federal e/ou buscado contribuir com o campo de estudos comparativos internacionais.

Somado a isso, dadas as características do nosso federalismo, pesquisadores começaram a investigar as "capacidades" nos planos subnacionais. É o caso de

\footnotetext{
${ }^{1}$ Resultados preliminares deste estudo foram apresentados em Seminário no Institute of Development Studies (IDS) em outubro de 2019. Os autores agradecem ao IDS e à CAPES pela viabilização da pesquisa bem como à Alex Shankland (IDS) pelos comentários críticos e ao seu cordial suporte junto à instituição inglesa. Agradecemos também os comentários dos revisores anônimos desta Revista.
} 
trabalhos como os de Souza (2018), que as investiga no plano estadual; e de Arretche (2012), Instituto Pólis (2013), Sátyro, Cunha e Campos (2016), Touchton, Sugiyama e Wampler, (2017), Marenco, Strohschoen e Joner (2017), Grin et al. (2018) e Souza, Rodrigues e Silva (2019), que lançam olhar sobre o plano municipal. De forma geral, esses trabalhos analisam os efeitos de elementos geradores de políticas (policy) sobre áreas específicas tais como habitação, assistência social, desenvolvimento e política urbana ou tributação e gestão financeira. Ainda que nem todos utilizem o conceito de capacidades estatais tal qual o mainstream da área, em conjunto, eles oferecem interessantes pistas analíticas para se definir quais elementos compõem as capacidades de gestões municipais.

Sendo este um primeiro e incipiente esforço dos autores, o artigo pretende contribuir com essa literatura. Os municípios brasileiros oferecem duas vantagens como caso para a análise das capacidades ao nível local. Primeiro, são responsáveis por uma vasta gama de serviços públicos e políticas sociais, ainda que os exercícios das atribuições dos governos locais possam ser limitados por arranjos em que a União exerça função de regulação, coordenação e supervisão (ARRETCHE; VAZQUEZ; GOMES, 2012). De qualquer forma, cabe questionar, tal como a literatura supracitada, sobre as especificidades locais. Segundo, há uma grande quantidade de dados disponíveis (ainda pouco explorados) sobre as gestões e as condições socioeconômicas de todos os municípios brasileiros (JANNUZZI, 2017; ATHIAs et al., 2019), o que permite mensurar possíveis componentes das capacidades governamentais municipais.

Assim, a contribuição do trabalho consiste em discutir como o conceito de capacidade estatal pode contribuir para análises no nível local e como mensurar suas dimensões. Para isso, adaptamos oframework teórico proposto por Gomide e Pires (2014) e Gomide, Pereira e Machado (2017) à realidade local e operacionalizamos os componentes do conceito por meio de variáveis institucionais objetivas, captadas pelas Pesquisas de Informações Básicas Municipais do IBGE (Munics). Pela perspectiva adotada, as capacidades estatais possuem duas dimensões: a técnico-administrativa e a político-relacional. A primeira, é composta por recursos humanos, recursos financeiros, instrumentos de planejamento e gestão, e estruturas de gestão. A segunda, por arranjos interfederativos, mecanismos de interação da burocracia com políticos, canais de participação da sociedade civil, e mecanismos de transparência e de controle interno e/ou externo. Buscamos identificar e 
construir variáveis empíricas que permitam mensurar esses componentes em três áreas de políticas públicas: saúde, educação e assistência social.

Por meio de um modelo de regressão logística, avaliamos se esses indicadores estão associados a variações nos níveis de desenvolvimento socioeconômico, expressos pelo Índice de Desenvolvimento Humano Municipal (IDH-M)². Os dados, que são detalhados na seção metodológica, são de meados da década de 2010. Para a construção do modelo, diante da grande heterogeneidade dos municípios, optamos por trabalhar com os de pequeno porte, isto é, de até 50 mil habitantes, que representam $85 \%$ das unidades de governo local. A pesquisa procura verificar se as capacidades municipais, mensuradas a partir das três áreas de políticas indicadas acima, contribuem para a explicar o nível de desenvolvimento humano no nível local. O modelo é aplicado tanto para o Brasil (a totalidade da amostra) quanto para cada uma de suas cinco macrorregiões (Norte, Nordeste, Centro-Oeste, Sudeste e Sul). A partir das evidências encontradas, nesta análise exploratória, sustentamos que os elementos mais fortemente associados a níveis mais altos de IDH-M são aqueles relacionados a atividades de planejamento, formação de parcerias com outros entes federativos e participação da sociedade civil. Ou seja, os elementos mais correlacionados com maiores níveis de IDH-M são aqueles que requerem ativismo estatal local.

O trabalho está estruturado em cinco seções, além desta introdução. Na segunda, fazemos uma discussão da literatura e apresentamos o framework teórico, em que realçamos as diferenças entre as duas dimensões das capacidades estatais e apresentamos os elementos que as compõem no nível local. Na terceira seção, apresentamos a metodologia e as variáveis que operacionalizam e permitem mensurar cada um dos componentes de cada dimensão. Na quarta, apresentamos e discutimos os resultados da análise. Finalmente, apresentamos as considerações finais e as implicações desses resultados.

\footnotetext{
${ }^{2} \mathrm{O}$ IDH-M foi desenvolvido através da parceria entre o Programa das Nações Unidas para o Desenvolvimento (PNUD), seccional do Brasil, o Instituto de Pesquisa Econômica Aplicada (Ipea) e a Fundação João Pinheiro (FJP). Ele adapta o IDH da ONU, usado para mensurar o desenvolvimento humano de países, para ser aplicado à realidade brasileira no nível dos municípios. O índice foi calculado com os dados dos censos demográficos do Instituto Brasileiro de Geografia e Estatística (IBGE) para três ciclos: 1991, 2000 e 2010. Mais informações: http://www.atlasbrasil.org.br/2013/pt/
} 


\section{Capacidades estatais municipais: framework teórico}

As discussões sobre capacidades estatais surgiram na década de 1970 como parte de um esforço por entender o que torna Estados efetivos. A amplitude e generalidade que o termo adquiriu, nos anos posteriores, permitiu que ele fosse trabalhado na academia de forma "multidimensional". Em revisão sobre essa literatura, Cingolani (2013), por exemplo, a divide pela ênfase em sete distintas dimensões: coercitiva, tributária/extrativa, administrativa/burocrática, transformativa, relacional, legal e política. Não apenas são muitas as dimensões passíveis de análise, como também os estudos variam em termos de nível (de micro à macro), abarcando desde formação do Estado (TILLY; ARDANT, 1975) até gestão fiscal local (MARENCO; StROHSCHOEN; JONER, 2017); passando por processos de industrialização (EVANS, 1995), crescimento econômico (EVANS; RAUCH, 1999) e implementação de acordos de paz (DERouEN JR et al., 2010). Essa multidimensionalidade leva a uma grande variedade de definições do conceito, o que lança desafios às análises (Cingolani, 2013; Gomide; Pereira; Machado, 2017; Aguiar; lima, 2019).

Apesar do amplo reconhecimento da capacidade estatal como um conceito multidimensional na literatura, há uma divergência considerável sobre como a desagregar a nível conceitual. Por exemplo, Brautigam (1996) define capacidade estatal como uma medida da capacidade de um governo de implementar suas políticas e objetivos, e a divide em quatro dimensões: capacidade regulatória, administrativa, técnica e extrativa. Lindvall e Teorell (2016) a definem como a força do relacionamento causal entre as políticas que os governos adotam e os resultados que pretendem alcançar, distinguindo entre as capacidades humanas, materiais e informacionais do Estado. Mas, enquanto eles focam no poder do Estado, Centeno et al. (2017) preferem falar em desempenho do estado e o dividem em ordem e alcance, desenvolvimento econômico e inclusão e equidade. Mais recentemente, quando Berwick e Christia (2018) tentam gerar uma estrutura geral relevante para o estudo e prática de construção de capacidade estatal, integrando abordagens clássicas e experimentais, elas destacam três tipos de capacidade: extrativa, coordenadora e de conformidade. Williams (2018) questiona ainda a utilidade do conceito para a análise do desempenho de burocracias governamentais e implementação de políticas. 
Se o conceito é tão amplo, por que então utilizá-lo? Primeiro, porque insere o estudo e suas reflexões em uma linha de pesquisa que tem oferecido interessantes insights a respeito da organização do Estado ao investigar como ele exerce seu poder de implementação de políticas públicas. Segundo, porque, ao situar esse debate no nível local, o conceito e as atuais discussões sobre seus desdobramentos, em nossa leitura, ajudam a compreender as gestões municipais, conectando-o com o conhecimento já produzido sobre descentralização e políticas públicas, debate que aqui tangenciamos, mas ainda permanece passível de aprofundamentos. A relevância desse exercício decorre do fato de que "sabemos pouco sobre como a burocracia municipal é configurada, menos ainda sobre sua capacidade de ação e quase nada dos seus efeitos nos serviços" (SÁTYRo; CUNHA; CAMPOS, 2016, p. 287).

A concepção de capacidades estatais que fundamenta nossa análise advém dos estudos de Pires e Gomide $(2014)^{3}$, que desenvolveram o conceito para analisar um conjunto de programas federais no Brasil. Escolhemos essa abordagem, pois ela traz a relevante noção de que as capacidades são permeadas por interações com múltiplos atores, que assegurariam a legitimidade das ações e teriam o potencial de gerar inovações. Elas podem se dar, por exemplo, na forma de participação social institucional, que se tornou relevante na implementação de políticas sociais no país; ou através da adoção de arranjos, formais ou informais, os quais conectam agências burocráticas do Poder Executivo com atores políticos no Poder Legislativo e na sociedade civil. Dessa forma, para Pires e Gomide (2014, s/p), capacidade estatal seria a "capacidade do Poder Executivo de implementar suas políticas envolvendo múltiplos atores e interesses".

Nessa perspectiva, o conceito envolve tanto a competência do Estado para implementar suas políticas quanto a autonomia e legitimidade para fixá-las através de processos democráticos, o que depende de duas dimensões: técnico-administrativa e político-relacional. A primeira diz respeito aos procedimentos e às competências dos agentes do Estado para levar a efeito suas políticas, definindo e determinando ações coordenadas e orientadas para a produção de resultados. Em outros termos, essa dimensão

\footnotetext{
${ }^{3}$ Inicialmente, esses autores desenvolveram a citada abordagem em dois capítulos do livro Capacidades estatais $e$ democracia: arranjos institucionais de políticas públicas (PIRES; GoMIDE, 2014; GOMIDE; PIRES, 2014). Posteriormente, aprofundaram-na em outras oportunidades em conjunto com outros colaboradores (PIRES; GOMIDE, 2016; GOMIDE; PEREIRA; MACHADO, 2017).
} 
é derivada da existência e do funcionamento de burocracias profissionais e autônomas, fundamentadas nos pressupostos da especialização das funções, da meritocracia, do formalismo, da hierarquia e da impessoalidade, as quais, dotadas dos devidos recursos organizacionais, financeiros e tecnológicos, são necessárias para conduzir as ações do governo. Ela segue a clássica lógica da burocracia weberiana, sob a qual se apoiou grande parte dos estudos pioneiros sobre a temática (EVANS, 1995; SKOCPOL, 1985).

Não obstante, em um contexto democrático, para que possa implementar suas políticas de forma legítima, não basta o Estado ser dotado de aparatos burocráticos. Isto é, uma burocracia profissional, embora necessária, não é suficiente. As ações do Estado devem gozar de legitimidade, ter respaldo na sociedade e ser construídas através de diálogo com atores sociais e do sistema representativo (PIRES; GOMIDE, 2014). Portanto, a segunda dimensão do conceito diz respeito às habilidades do governo em expandir os canais de interlocução e negociação com os diversos atores sociais, em processar conflitos, prevenindo a captura por interesses privados específicos e visando à criação de consensos mínimos sobre questões políticas complexas. Essa concepção, aliás, condiz com outras encontradas na literatura, como Mann (1984), Evans (1995), Edigheji (2010), Heller (2011) e Souza (2016).

Com base nesses pressupostos, as capacidades municipais podem ser compreendidas como as habilidades dos governos locais de planejar, implementar e manter políticas sociais, o que envolve múltiplos atores e interesses. Mas, como podemos medi-las? É preciso considerar que, tal qual a capacidade estatal, se, por um lado, o conceito "tem caráter latente e, portanto, não [é] observável diretamente", por outro, seus componentes podem ser operacionalizados em variáveis empíricas, como sugerem Gomide, Pereira e Machado (2017, p. 86). Quais poderiam ser, então, seus elementos constitutivos e suas proxies empíricas?

Conforme exposto acima, o conceito se desdobra em duas dimensões: técnicoadministrativa, relacionada às noções de eficiência e eficácia; e político-relacional, associada às noções de legitimidade e inovação. De forma objetiva, entre outros possíveis fatores, a primeira seria composta por: recursos humanos; recursos financeiros; instrumentos de planejamento e gestão; e estruturas de gestão. Já segunda se constituiria de: arranjos (interfederativos, intramunicipais e intermunicipais); mecanismos de 
interação da burocracia do Executivo com atores do sistema político-representativo; canais de participação; e mecanismos de transparência e de controle interno e/ou externo. O conceito, suas dimensões e indicadores podem ser representados pelo esquema a seguir (Figura 1):

Figura 1 | Componentes das capacidades governamentais municipais

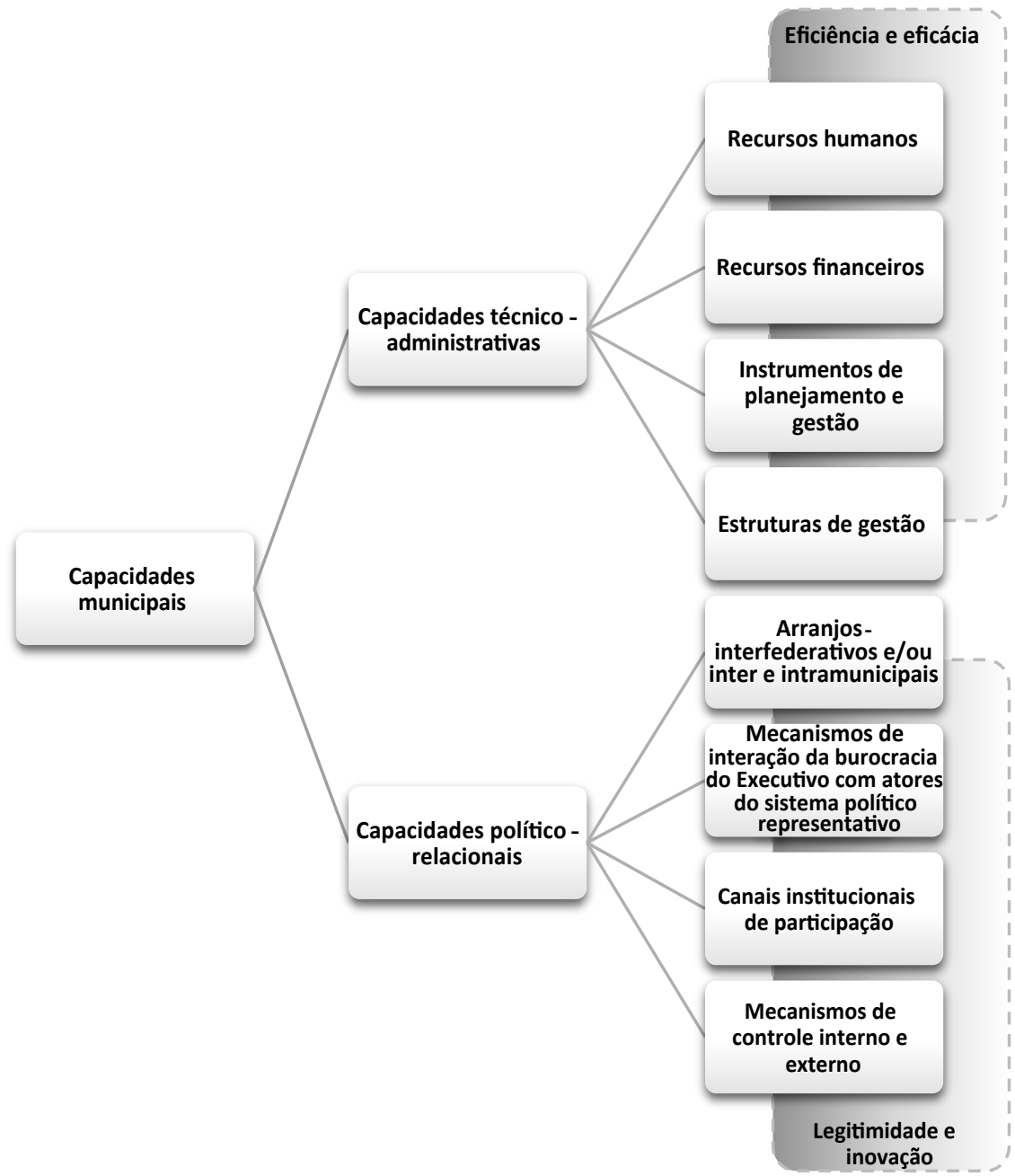

Fonte: Elaboração própria, adaptado de Gomide, Pereira e Machado (2017).

Se, no plano teórico, a discussão se ancora principalmente nas pesquisas de Pires e Gomide (2014) e Gomide, Pereira e Machado (2017), a escolha dos indicadores para as análises empíricas, por sua vez, foi baseada em trabalhos que analisam os efeitos de 
capacidades de gestão em níveis subnacionais sobre áreas específicas de políticas públicas. Em conjunto, eles oferecem um panorama e pistas importantes para definir elementos empíricos das capacidades presentes nos municípios.

Por exemplo, ao estudar as capacidades administrativas municipais para a política habitacional, Arretche (2012) elenca cinco indicadores que permitem analisar a existência e a trajetória de instrumentos de gestão local nessa política: i) órgãos destinados à gestão da política; ii) cadastros próprios e/ou fontes de informação para a identificação do déficit municipal de moradias; iii) consórcios intermunicipais de habitação; iv) instâncias de participação popular; v) fundos específicos para a política. No relatório $O$ estado das cidades no Brasil, publicação coordenada pelo Instituto Pólis (2013, p. 46), pesquisadores procuraram analisar "as condições urbanas no Brasil", dedicando um capítulo à "gestão municipal do desenvolvimento urbano", a partir de 4 indicadores: i) instrumentos de gestão, como planos diretores; ii) estruturas, como secretarias; iii) canais institucionais de participação; iv) arranjos federativos, como a existência de consórcios. Por fim, Sátyro, Cunha e Campos (2016) analisaram as capacidades de implementação e gestão da política de assistência social nos municípios com base em características dos recursos humanos, mesma estratégia usada por Marenco, Strohschoen e Joner (2017), e por Souza (2018). Para tanto, trabalham com dados relativos aos vínculos empregatícios dos trabalhadores dessa área, à sua inserção na estrutura formal e aos seus graus de educação.

No presente trabalho, os indicadores utilizados por esses autores foram coligidos com os dados dispostos nas Pesquisas de Informações Básicas Municipais (Munics), que, realizadas periodicamente pelo IBGE desde 1999, consistem em um levantamento de informações sobre a estrutura, a dinâmica e o funcionamento das instituições públicas do conjunto de municípios brasileiros. Apesar das limitações dessas pesquisas ${ }^{4}$ (JANNUZZI, 2017; ATHIAs et al., 2019), elas fornecem as melhores evidências empíricas disponíveis.

Assim, a partir dos subsídios teóricos apresentados e da disponibilidade dos

\footnotetext{
${ }^{4}$ Uma das principais críticas direcionadas às Munics é a de que o seu informante principal é a própria prefeitura através dos seus diversos órgãos e setores. Isso significa que as informações coletadas são respondidas por diferentes pessoas de dentro da administração, responsáveis e/ou detentoras de maior conhecimento em cada área. Segundo os críticos, essa metodologia tende a distorcer os dados de forma a melhorar a imagem da gestão. Mas, como demonstra Jannuzz (2017), essas pesquisas têm sido fundamentais para compreender melhor aspectos da gestão pública brasileira e vêm sendo amplamente utilizadas no meio acadêmico.
} 
dados, adotamos as seguintes proxies para cada um dos indicadores do esquema acima: i) recursos humanos: percentagem de funcionários concursados com ensino superior na administração direta; ii) recursos financeiros: adoção de fundos; iii) instrumentos de planejamento e gestão: adoção de planos municipais de políticas públicas; iv) estruturas de gestão: adoção de secretarias municipais exclusivas; $v$ ) arranjos: adoção de consórcios; vi) canais de participação: adoção de conselhos. Uma melhor descrição dessas variáveis empíricas é fornecida na seção metodológica a seguir.

Por fim, vale indicar que, ao invés de tomar como base uma única área específica, procuramos generalizar as estratégias tomadas pelos autores supracitados e abranger um arco intersetorial. Analisamos esses diferentes elementos apontados para três diferentes áreas de políticas públicas: saúde, educação e assistência social. Isso porque, como sugerem Sposati et al. (1996) e Sposati e Toledo (2001), embora a lógica do Estado seja o do oferecimento setorizado das políticas governamentais, a lógica dos cidadãos e cidadãs é buscar o fornecimento de bens e serviços públicos e o atendimento de suas necessidades básicas em sua integralidade a partir de sua base territorial de referência, de seu local de moradia na cidade. É dessa perspectiva que procuramos analisar as possíveis correlações entre capacidades de gestão e desenvolvimento humano locais.

\section{Metodologia e Variáveis}

Com o propósito de verificar as correlações do desenvolvimento humano local em função das capacidades estatais municipais, utilizamos regressões logísticas ordenadas (também conhecidas como "acumuladas") para verificar a relação entre o IDH-M e os elementos decompostos das capacidades estatais para os quais temos dados disponíveis nessa fase da pesquisa. Além disso, criamos uma série de tabelas de frequência (não reportadas integralmente no artigo) e realizamos a distribuição geoespacial de elementos selecionados com o objetivo de melhor demonstrar e ilustrar os resultados alcançados. Foram analisadas todas as localidades com menos de 50 mil habitantes, o que corresponde a 4.916 dos 5.570 municípios brasileiros, ou 85\% do total. A opção por esse recorte inicial deveu-se ao objetivo de reduzir a grande heterogeneidade dos perfis socioeconômicos e demográficos, mitigando a presença de outliers na análise. Em contrapartida, apenas 32\% 
da população vive nesses municípios, o que limita o alcance da análise e requer cautela na interpretação dos resultados. As regressões e tabulações foram aplicadas tanto para o total da amostra, o conjunto dos entes federados locais analisados (Brasil), quanto para cada macrorregião distinta (Norte, Nordeste, Centro-Oeste, Sudeste e Sul).

\section{Variável dependente}

A variável de resposta é o IDH-M, calculado por meio da agregação de indicadores de longevidade, educação e renda. O índice varia de 0 , o menor nível de desenvolvimento humano, a 1, o maior. Conforme o valor, o IDH-M dos municípios é classificado como: "muito baixo"; "baixo"; "médio"; "alto"; e "muito alto". Entre 1991 e 2010, o país aumentou em 47,5\% o seu IDH-M médio, passando de 0.493 (considerado "muito baixo") para 0.727 (considerado "alto"), embora a heterogeneidade entre as regiões seja bastante elevada (BRASIL, 2013). Obviamente, a evolução desse indicador se deveu a múltiplos e complexos fatores, entre os quais podem-se citar as políticas de estabilização da moeda e as políticas sociais adotadas pelo Governo Federal no período (ARRETCHE, 2015), além de fenômenos macroeconômicos internacionais. Não obstante, da perspectiva de análise aqui sugerida e adotada, torna-se relevante perguntar se e como o Estado mobilizou suas capacidades para operar e orientar tais transformações também no nível da gestão territorial local.

Para operacionalizar essa variável, devido à necessidade de ajuste ao modelo logístico empregado (YEE, 2010), em vez de trabalharmos com as gradações oficiais, trabalhamos com os quintis da distribuição observada ${ }^{5}$, ordenados de forma crescente. No modelo, a variável dependente é o log das chances $\left(\log\right.$ of odds) ${ }^{6}$ de o município ser

\footnotetext{
${ }^{5}$ Pela classificação do Atlas Brasil, dentre os 4.916 municípios analisados, apenas 30 se enquadram na classificação "muito baixo" e 5, na "muito alto". Isso gera alta concentração nas categorias intermediárias ("baixo" = 1.316; "médio"= 2.054 e "alto" = 1.511). Ao adotar a classificação por quintis, aproximadamente $25 \%$ dos valores ficam classificados em cada uma das categoriais, o que representa uma distribuição mais homogênea entre as categorias e permite a melhor aplicação do modelo logístico de regressão.

${ }^{6} \mathrm{O}$ uso de log das chances em vez da probabilidade é comum por causa da dificuldade de se modelar uma variável que varie entre 0 e 1. Para entender o que o log das chances significa, tomemos o exemplo de um evento com probabilidade de sucesso de 0,8 . Então a probabilidade de falha é $1-0,8=0,2$. As chances de sucesso são a razão entre a probabilidade de sucesso e a probabilidade de falha. No nosso exemplo, 0,8 / 0,2 = 4, ou seja, as chances de sucesso são de 4 para 1 . Se a probabilidade de sucesso for de 0,5 (50\% para sucesso e $50 \%$ para fracasso), então as chances de sucesso são de 1 para 1. As chances variam de 0 a infinito positivo. Com log das chances, os resultados variam de menos infinito a mais infinito. À medida que a probabilidade aumenta, aumentam as chances e também o log das chances (https://stats.idre.ucla.edu/ other/mult-pkg/faq/general/faq-how-do-i-interpret-odds-ratios-in-logistic-regression/).
} 
classificado acima de certa faixa de IDH-M. Os dados são os do último cálculo realizado para todos os municípios (2013, com base no Censo Demográfico de 2010, cf. nota 2).

\section{Variáveis de controle}

Adotamos o PIB per capita municipal como variável de controle, pois, como seria de se esperar, e testes estatísticos previamente realizados endossaram, ele apresenta forte associação positiva com a variável dependente. Ou seja, quanto maior o PIB per capita, maior o nível de IDH-M. O PIB per capita é estaticamente significante e, como esperado, possui forte relação positiva com o índice de desenvolvimento. Isso tanto para o Brasil como para cada região específica (Tabela 1). Os dados, do ano de 2012, são disponibilizados pelo IBGE.

\section{Variáveis independentes}

Conforme apresentado na seção 2, capacidades no nível local possuem duas dimensões: técnico-administrativa e político-relacional. Para cada um dos componentes dessas dimensões foi selecionado uma proxy empírica que nos permite mensurá-la, as quais serão apresentadas a seguir. As exceções são os mecanismos de interação da burocracia do Executivo com atores do sistema político e os mecanismos de controle interno e externo, pois, nessa fase da pesquisa, não incluímos indicadores para esses componentes. No primeiro caso, a não inclusão decorre da falta de um indicador e de dados que expressassem adequadamente a variável. No segundo, o principal órgão de controle dos municípios de até 50 mil habitantes é a Controladoria Geral da União (CGU), que fiscaliza por amostragem o uso de recursos federais em todas localidades do país ${ }^{7}$. Como todos os órgãos são submetidos à CGU, não há variação que possa ajudar a explicar variações no IDH-M.

As informações referentes a todas as demais variáveis independentes são provenientes das Pesquisas de Informações Básicas Municipais do IBGE (Munics) dos anos entre 2013 e 2015. Todas elas dizem respeito às três áreas analisadas: saúde, educação e assistência social.

\footnotetext{
${ }^{7}$ Apenas os municípios do Rio de Janeiro e de São Paulo possuem tribunais de contas municipais próprios. Os estados da Bahia, Goiás e Pará possuem tribunais de contas dos municípios dos estados, ou seja, órgãos estaduais com a função de fiscalizar os municípios.
} 


\section{Recursos humanos}

A proxy de recursos humanos utilizada consiste na porcentagem de funcionários da administração direta que são concursados e possuem educação superior, tal qual utilizada por Marenco, Strohschoen e Joner (2017). Nos questionários das Munics são identificados como "estatutários" com "ensino superior", o que também inclui pós-graduações. São funcionários estatutários aqueles contratados sob as regras do Regime Jurídico Único, cuja seleção se dá por meio de concurso público. Como regra geral, tais servidores obtêm estabilidade no cargo após três anos de estágio probatório. Segundo os autores, essas características se aproximam da categoria burocracias profissionais, que contempla duas dimensões: a autonomia, fundada em carreiras estáveis e recrutamento baseado em mérito; e a capacidade técnica, que considera indicadores de desempenho profissional. Em suma, "a combinação 'estatutário' com 'formação superior' pode representar uma proxy para identificação de uma burocracia profissional orientada racionalmente" (MARENCO; Strohschoen; JONER, 2017, p. 1039). Assim, partimos da premissa, compartilhada por parte importante da literatura sobre o tema (EVANS; RAUCH, 1999; SÁTYRO; CUNHA; CAmpos, 2016; MAREnco; Strohschoen; Joner, 2017), de que essas características conferem à administração pública atributos de autonomia, estabilidade e especialização que o aproximam do tipo ideal weberiano de burocracia profissional e que constituem os recursos humanos no nosso modelo na dimensão técnico-administrativa.

\section{Recursos financeiros}

Uma vez que o PIB per capita consta nos modelos como variável de controle em vez de independente, e que recursos orçamentários possuem alta correlação com o PIB per capita, a proxy de recursos financeiros utilizada foi a presença de fundo municipal nas três áreas. Apesar de serem distintas as finalidades dos fundos de um setor de política pública para outro, em geral, eles são criados para abrigar receitas vinculadas à realização de determinados objetivos ou serviços específicos. Assim, os fundos setoriais pretendem proteger o gasto nas políticas sociais da disputa por recursos com outras áreas de políticas. Procuram assegurar que "as transferências federais contem com garantias críveis de que os recursos serão efetivamente empregados para as políticas a que se destinam" (ARRETCHE, 2012, p. 18). Vale dizer que a criação de fundos (tal qual a de conselhos e 
planos municipais) é incentivada pelo modelo federativo indutivo de descentralização nas áreas de políticas públicas analisadas.

A existência de fundo em cada uma das áreas recebeu valor 1 e a não existência recebeu valor 0 . Eles foram somados e recodificados, criando-se a variável categórica ordenada: "não possui", "possui 1", "possui 2" ou "possui 3", conforme a respectiva quantidade. Esse mesmo procedimento foi aplicado para todas as demais variáveis independentes categóricas do modelo (instrumentos de planejamento; estruturas de gestão e canais de participação).

\section{Instrumentos de planejamento e gestão}

Como proxy de instrumentos de planejamento e gestão, foi utilizada a existência de planos municipais de políticas públicas. Estes são documentos setoriais orientadores que estabelecem metas e estratégias de médio e longo prazos. Em geral, preveem como os recursos podem ser utilizados, regulamentam e orientam as proposições e execuções das políticas municipais do setor; contêm diretrizes e metas a serem alcançadas; e prescrevem formas de colaboração com a União, estados, demais municípios, setor privado e organizações sociais, e de participação da sociedade civil, entre outros pontos.

\section{Estruturas de gestão}

Para o indicador estrutura de gestão foi utilizada a "existência de secretarias exclusivas". Secretarias são órgãos do governo municipal responsáveis por formular e executar a política setorial. Em seu âmbito, são abrigados os recursos humanos e financeiros e são desempenhados papéis de coordenação com outras instâncias. Por exemplo, em geral, a elas estão vinculados os canais de participação do setor, como os conselhos. Analisando as capacidades administrativas na área da habitação, Arretche (2012, p. 36) pressupõem que "a existência de uma secretaria própria permitiria maior efetividade às políticas habitacionais, dada a existência de burocracias especializadas e dedicadas à captação de recursos, produção e gestão de serviços". Esse estatuto jurídico do órgão permitiria identificar o espaço institucional e a centralidade da política setorial (em relação a outras existentes) na agenda municipal. Essa pressuposição foi aqui generalizada para todas as áreas. Assim, a existência de secretaria exclusiva recebeu nota 


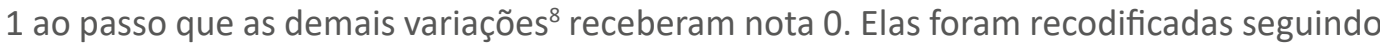
o procedimento descrito anteriormente.

\section{Arranjos institucionais}

Para os arranjos institucionais, utilizamos a existência de consórcios nos municípios (sejam eles com o Governo Federal, estadual ou de outros municípios). Os consórcios são parcerias formadas entre os entes federativos e visam à provisão de serviços. Eles funcionam como o veículo para a implementação de soluções conjuntas e coordenadas para resolver, de maneira integrada, dificuldades que individualmente seriam mais difíceis de ser superadas. Ou seja, consórcios permitem a geração de economias de escala na administração pública, possibilitando uma maior eficiência e na aplicação de recursos existentes e melhor qualidade na prestação de serviços (CUNHA, 2004). Por exemplo, os consórcios intramunicipais são iniciativas de municípios localizados em uma mesma região que se associam para gerir e prover conjuntamente serviços à população das cidades participantes. Na área da saúde, podem estar voltados ao provimento de especialistas médicos ou serviços e equipamentos de maior complexidade e alto custo, que os entes isoladamente teriam maior dificuldade de custear (RIBEIRO; COSTA, 2000).

\section{Canais de participação}

Como indicador de participação social, foi utilizada a existência ou não de conselhos gestores nas três áreas. Os conselhos são colegiados híbridos, formados por representantes do governo e da sociedade civil, que têm entre suas funções aumentar o controle público sobre as gestões governamentais, fiscalizando a aplicação dos recursos financeiros de suas áreas e verificando a implementação da política. Também são considerados espaços de inclusão de novos atores na área política institucional. Para as áreas aqui consideradas, essas instâncias têm caráter deliberativo, ou seja, "efetivamente, têm poder de decidir sobre a implantação de políticas e/ou administração de recursos relativos à sua área de atuação" (COELHo et al., 2019, p. 3). Isso quer dizer, por exemplo, que a utilização dos recursos dos fundos deve ser aprovada por esses órgãos, compulsoriedade vinculada

\footnotetext{
${ }^{8}$ Tais variações são as seguintes: Secretaria municipal em conjunto com outras políticas setoriais; Fundação pública; Setor subordinado a outra secretaria; Setor subordinado diretamente à chefia do Executivo; Não possui estrutura.
} 
à continuidade do repasse de recursos federais (CORTES, 2011; LAVALLE; BARONE, 2015). Portanto, são instâncias criadas como canais de participação, fiscalização e controle do poder público pela sociedade civil.

Diante do exposto, o modelo utilizado foi o seguinte:

$\ln \ln \left(\frac{P}{1-P}\right)=b_{0}+b_{1} H+b_{2} F+b_{3} P l+b_{4} M+b_{5} C s+b_{6} C o+b_{7} P I B$

Onde,

- $\quad \mathrm{P}=$ probabilidade de o município ser classificado em certo nível de IDH-M;

- $\quad H=\%$ do total de funcionários que são concursados e com curso superior;

- $\quad \mathrm{F}$ = número de fundos exclusivos para as áreas analisadas;

- $\quad \mathrm{PI}=$ número de planos municipais para as áreas analisadas;

- $\quad M=$ número de secretarias exclusivas para as áreas analisadas;

- $\quad$ Cs = número áreas beneficiadas por consórcios;

- $\quad$ Co = número de conselhos municipais para as áreas analisadas;

- $\quad \mathrm{PIB}=\mathrm{PIB}$ per capita do município.

\section{Análise}

Os resultados indicam que todas as variáveis independentes são estatisticamente significantes ao nível de confiança de 0,001, exceto existência de fundos dedicados às áreas avaliadas. A não significância dessa variável pode ser decorrente de sua baixa variabilidade, uma vez que, entre os municípios com menos de 50 mil habitantes, 97,8\% possuem os 3 fundos (Mapa 1). Esse fenômeno indica o forte efeito de indução federal nessa política. Independentemente de os municípios terem autonomia para realizar a 
criação dos fundos ou não, sem eles ficam inviabilizados os repasses de recursos federais para as áreas.

Em relação à direção da associação de cada uma das demais variáveis explicativas, os resultados sugerem que os elementos constitutivos propostos para as capacidades estatais municipais apresentam correlações ambivalentes à variação do IDH-M. Enquanto a presença de conselhos, consórcios e planos municipais apresentaram coeficientes positivos, aqueles referentes à quantidade de secretarias exclusivas e porcentagem de funcionários públicos na administração direta apresentaram sinais negativos. Os resultados mostram ainda que, no lado positivo da equação, os conselhos possuem uma relação mais forte com o IDH-M, seguidos dos consórcios e planos. No lado oposto, as secretarias possuem associação mais forte, ao passo que a proporção de servidores concursados com nível superior tende à neutralidade. Destaca-se que os resultados não representam causalidade, mas apenas correlação. Os resultados são sumarizados na Tabela 1 tanto para o Brasil quanto para cada Região. 
Tabela 1 | Modelos logísticos ordenados - Brasil e Regiões, municípios com menos de $\mathbf{5 0 . 0 0 0}$ habitantes

\begin{tabular}{|c|c|c|c|c|c|c|c|}
\hline & & $\begin{array}{l}\text { Brasil } \\
\mathrm{N}=4.916\end{array}$ & $\begin{array}{l}\text { Norte } \\
N=379\end{array}$ & $\begin{array}{l}\text { Nordeste } \\
N=1.610\end{array}$ & $\begin{array}{l}\text { Centro- } \\
\text { Oeste } \\
\mathrm{N}=426\end{array}$ & $\begin{array}{l}\text { Sudeste } \\
\mathrm{N}=1.419\end{array}$ & $\begin{array}{l}\text { Sul } \\
\mathrm{N}=1.082\end{array}$ \\
\hline & $\begin{array}{l}\text { Pib per } \\
\text { capita } \\
\text { (log) }\end{array}$ & $\begin{array}{l}3.05200 * * * \\
0.06513\end{array}$ & $\begin{array}{l}2.7549 * * * \\
0.2749\end{array}$ & $\begin{array}{l}1.75707^{* * *} \\
0.13839\end{array}$ & $\begin{array}{l}1.2170^{* * *} \\
0.2038\end{array}$ & $\begin{array}{l}2.40247^{* * *} \\
0.12650\end{array}$ & $\begin{array}{l}2.41561^{* * * *} \\
0.18298\end{array}$ \\
\hline \multirow{4}{*}{$\begin{array}{l}\text { Capacida- } \\
\text { des técnico- } \\
\text {-administra- } \\
\text { tivas }\end{array}$} & Secretarias & $\begin{array}{l}-0.20377^{* * * *} \\
0.03551\end{array}$ & & & & $\begin{array}{l}-0.14373^{*} \\
0.06601\end{array}$ & $\begin{array}{l}-0.28686 * * * \\
0.06618\end{array}$ \\
\hline & Planos & $\begin{array}{l}0.25482^{* * *} \\
0.05112\end{array}$ & & $\begin{array}{l}0.33866 * * * \\
0.09999\end{array}$ & & & \\
\hline & Servidores & $\begin{array}{l}-0.00945^{* * *} \\
0.00240\end{array}$ & & & $\begin{array}{l}0.0243^{*} \\
0.0103\end{array}$ & & \\
\hline & Fundos & & & & & $\begin{array}{l}0.98263^{*} \\
0.42293\end{array}$ & \\
\hline \multirow{7}{*}{$\begin{array}{l}\text { Capacida- } \\
\text { des político- } \\
\text {-relacionais }\end{array}$} & Conselhos & $\begin{array}{l}0.53491 * * * \\
0.08314\end{array}$ & & $\begin{array}{l}0.61686^{* * *} \\
0.17374\end{array}$ & $\begin{array}{l}0.4980 * \\
0.2225\end{array}$ & $\begin{array}{c}0.81594 * * * \\
0.17529\end{array}$ & \\
\hline & Consórcios & $\begin{array}{l}0.27208 * * * \\
0.02732\end{array}$ & & $\begin{array}{l}0.18534 * * * \\
0.05349\end{array}$ & $\begin{array}{l}-0.3659 * * * \\
0.0977\end{array}$ & $\begin{array}{l}-0.44531 * * * \\
0.05997\end{array}$ & \\
\hline & (Intercept):1 & $\begin{array}{l}-29.07245^{* * *} \\
0.84376\end{array}$ & $\begin{array}{l}-25.2515^{* * *} \\
2.7976\end{array}$ & $\begin{array}{l}-17.84701 * * * \\
1.76706\end{array}$ & $\begin{array}{l}-10.9378 * * * \\
2.6897\end{array}$ & $\begin{array}{l}-22.77240 * * * \\
1.75118\end{array}$ & $\begin{array}{l}-16.42075^{* * *} \\
2.48718\end{array}$ \\
\hline & (Intercept):2 & $\begin{array}{l}-30.74508^{* * *} \\
0.85564\end{array}$ & $\begin{array}{l}-27.0632 * * * \\
2.8419\end{array}$ & $\begin{array}{l}-20.39154 * * * \\
1.79227\end{array}$ & $\begin{array}{l}-13.4475 * * * \\
2.6139\end{array}$ & $\begin{array}{l}-24.68077^{* * *} \\
1.75860\end{array}$ & $\begin{array}{l}-19.27195^{* * *} \\
2.39103\end{array}$ \\
\hline & (Intercept):3 & $\begin{array}{l}-32.36973^{* * *} \\
0.86997\end{array}$ & $\begin{array}{l}-29.7981^{* * * *} \\
2.9292\end{array}$ & $\begin{array}{l}-23.47782 * * * \\
1.85667\end{array}$ & $\begin{array}{l}\text { *-16.0285*** } \\
2.6419\end{array}$ & $\begin{array}{l}-26.76196 * * * \\
1.78143\end{array}$ & $\begin{array}{l}-21.66904 * * * \\
2.39679\end{array}$ \\
\hline & (Intercept):4 & $\begin{array}{l}-34.01782 * * * \\
0.88299\end{array}$ & $\begin{array}{l}-31.8281 * * * \\
3.0465\end{array}$ & & $\begin{array}{l}-18.6300 * * * \\
2.6923\end{array}$ & $\begin{array}{l}-28.42427^{* * *} \\
1.79937\end{array}$ & $\begin{array}{l}-23.49665^{* * *} \\
2.41387\end{array}$ \\
\hline & $\begin{array}{l}\text { Log- } \\
\text { likelihood }\end{array}$ & $\begin{array}{l}-5456 \text { on } \\
18089 \text { degrees } \\
\text { of freedom }\end{array}$ & $\begin{array}{l}\text {-379 on } 1409 \\
\text { degrees of } \\
\text { freedom }\end{array}$ & $\begin{array}{l}1208 \text { on } 4112 \\
\text { degrees of } \\
\text { freedom }\end{array}$ & $\begin{array}{l}\text {-406 on } 1485 \\
\text { degrees of } \\
\text { freedom }\end{array}$ & $\begin{array}{l}-1601 \text { on } 5497 \\
\text { degrees of } \\
\text { freedom }\end{array}$ & $\begin{array}{l}\text { 7-1102 on } 4205 \\
\text { degrees of } \\
\text { freedom }\end{array}$ \\
\hline
\end{tabular}

Códigos de significância: ‘***’ $0.001 ;^{\prime * * \prime} 0.01{ }^{\prime * \prime} 0.05$

Modelos operados com a função $\mathrm{vg} / \mathrm{m}$ do pacote Vgam (YEE, 2010).

Fonte: Elaboração própria, a partir de Munics 2013-2015, PIB (IBGE) e Atlas Brasil (2013).

Entre os pontos que mais chamam a atenção, os dados sugerem a relevância da existência de conselhos, nas áreas de educação, saúde e assistência social, na performance 
do IDH-M. Esse componente da capacidade estatal municipal é o que mais explica, entre as variáveis independentes, a variação na probabilidade de classificação do município em cada quintil do IDH-M e mostra-se o mais relevante do modelo. Isto é, quanto mais conselhos, maior a probabilidade de um município estar nos estratos superiores de IDH-M. Atualmente, $86,7 \%$ dos municípios contam com conselhos para as três áreas avaliadas. Porém, tomando por base os quintis superior e inferior, tem-se que, dentre os municípios classificados no último quintil, 94\% dos municípios possuem os 3 conselhos, 5\% possuem 2 e apenas $0,1 \%$ possui 1 conselho somente. No quintil inferior, esses valores são de $79,4 \%$ e 20,6\%, respectivamente, para 3 e 2 conselhos. Considerando a existência dos três conselhos, a diferença entre o primeiro e último quintil é de aproximadamente $15 \%$.

O modelo apresentou a relevância dessa variável não só para a amostra como um todo, mas também para as Regiões Nordeste, Centro-Oeste e, com maior força, Sudeste. Dos 1.419 municípios que compõem essa Região, 90,2\% possuem 3 e 9,8\% 2 conselhos. No extremo oposto, para efeito comparativo, dos 379 municípios da Região Norte (em cujo modelo a variável não possui significância), apenas $68,6 \%$ possuem os três conselhos (mapa apresentado na Figura 2).

Em termos gerais, os resultados aqui reportados encontram correspondência em outras pesquisas que avaliaram o efeito dos conselhos em políticas públicas específicas. Toughton, Suiyama e Wampler (2017) demonstraram haver associações significativas e positivas entre a implementação de conselhos não discricionários e redução da mortalidade infantil. Galvão e Soares (2017) encontraram associação entre a adoção de conselhos para pessoas com deficiência e o melhor desempenho dessa política nos municípios. Para Toughton, Wampler e Peixoto (2019), existe uma relação significativa entre a adoção de conselhos e maiores taxas de arrecadação de impostos. Dizem eles: "our statistical analysis indicates that Brazilian municipalities that voluntarily adopt participatory institutions collect significantly higher levels of taxes than other, similar municipalities without these institutions" (Toughton; WaMPler; Peixoto, 2019, p. 3). Por fim, Coelho et al. (2019) procuram construir um índice de potencial da participação conselhista no Brasil (IPPC), analisando 14 diferentes conselhos, e também encontram relação positiva com o IDH-M dos municípios, especialmente em seus níveis extremos superiores. Embora enfatizem que não se trata de uma relação de causalidade, segundo os autores, 93\% dos municípios de maior IDH-M (segundo a classificação do IBGE) apresentam um IPPC "alto" ou "muito 
alto; $87,5 \%$ dos municípios de IDH-M "muito baixo" apresentam IPPC abaixo de "médio". Não obstante, nos níveis intermediários (alto-médio-baixo) essa relação é um pouco mais diluída, mas ainda assim positiva.

Embora os casos citados na literatura sejam diferentes dos aqui tratados (em termos empíricos, teóricos e metodológicos), eles apontam na mesma direção. Os resultados sugerem que, em suma, esse fator da dimensão político-relacional das capacidades estatais municipais tem associação significativa e positiva com os maiores níveis do indicador de desenvolvimento humano local. É possível que municípios com níveis de IDH-M mais elevados proporcionem mais oportunidades para a participação. No entanto, uma explicação que corrobora a literatura está associada à seguinte lógica: conselhos controlam os recursos públicos e desempenham importante papel nos processos de monitoramento e inovação ao incluir novos atores conhecedores das realidades locais. De modo geral, a participação por meio de conselhos constitui um importante mecanismo de accountability social que auxilia na produção de políticas mais inclusivas e efetivas (TOUCHTON; SUGIYAMA; WAMPLER, 2017).

Outro fator da dimensão político-relacional que apresenta relação significativa e positiva com os níveis superiores de IDH-M é a adoção de arranjos institucionais, representados no modelo pelos consórcios. Embora grande parte dos municípios analisados não possuam nenhum consórcio ( 2.366 ou 48\%), dentre aqueles que possuem e estão enquadrados no quintil superior, 6 possuem apenas 1 desses arranjos, 544 possuem dois e 51 os possuem nas três áreas analisadas. Diversos autores têm destacado a importância de canais de interação institucional verticais e horizontais para a construção de capacidades de implementação de políticas e fornecimento de serviços, como Repetto (2004), Ribeiro e Costa (2000) e Lotta e Vaz (2015). Os resultados do nosso modelo reforçam a influência positiva desses canais. O sinal positivo encontrado pode ser resultado dos processos de articulação e coordenação próprios desses arranjos. Eles tendem a envolver atores e otimizar recursos, ao definir quem são e estabelecer os papéis e a forma de interação na produção de uma ação, um plano ou programa governamental específico (PIRES; GOMIDE, 2016). Tendem a gerar economia de escala ao diminuir valores que para os entes isolados seriam muito custosos.

Também a existência de planos municipais, de acordo com o nosso modelo, possui influência de magnitude semelhante à dos consórcios na classificação do município nos 
quintis superiores de IDH-M. Na distribuição de frequências, entre os municípios de maior quintil de IDH-M, 47,4\% possuem planos de políticas públicas nas três áreas analisadas, ao passo que no quintil de menor IDH-M, são apenas $24,4 \%$ os que possuem os planos nas três áreas. Como ressaltado pelo campo de políticas públicas, o planejamento é uma etapa fundamental do processo de produção de políticas públicas. Segundo Oliveira (2006), ele deve ser visto não como um ato estritamente burocrático ou economicista, mas um processo de decisão político-social, que deve levar em conta informações precisas, capacidade de articulação e compreensão do processo e dos temas debatidos pelos diversos atores envolvidos. Aliás, no Brasil, não é incomum que planos sejam gerados a partir de diretrizes retiradas de conferências municipais ou deliberações de conselhos.

Do outro lado da ambivalência, o número de secretarias exclusivas apresentou uma relação negativa com o IDH-M. A maior parte dos municípios nos quintis superiores de IDH-M possuem duas secretarias. Os resultados parecem corroborar os encontrados por Veloso et al. (2011), em que a capacidade de gestão financeira é inversamente relacionada à existência de secretarias exclusivas da pasta. Nesse estudo, a maior parte dos municípios que terceirizam serviços de gestão financeira são justamente os que possuem secretarias exclusivas para a pasta. É possível ainda que a relação entre secretarias exclusivas e capacidade estatal local possua relação causal inversa. Ou seja, possivelmente onde a capacidade de gestão e entrega de serviços é menor, a pressão pela criação de secretarias exclusivas seja maior, visando conferir prioridade para os temas das pastas.

O resultado encontrado para as estruturas de gestão é influenciado fortemente pelos resultados das Regiões Sudeste e Sul. Como se pode visualizar na distribuição geoespacial a seguir (Figura 2), nessa última Região, há uma alta incidência de municípios sem nenhuma ou com apenas uma secretaria exclusiva para as áreas analisadas (particularmente no Rio Grande do Sul e Santa Catarina), embora apresente altos níveis de IDH-M. Isso sugere que nessas regiões outras estruturas organizacionais são adotadas para a implementação das políticas, sendo necessárias investigações mais aprofundadas sobre o ponto.

Em simulações excluindo a Região Sul, a variável deixa de apresentar significância. Não obstante, é necessária alguma cautela com relação a esses resultados, pois o número de secretarias pode variar significativamente no tempo e os dados utilizados são referentes apenas aos anos de 2013-2015. Conforme aponta Arretche (2012, p. 74), uma das principais 
decisões de novas administrações municipais é sobre a criação de estruturas exclusivas ou em conjunto com outras pastas, e na forma de secretarias, coordenações ou outras estruturas $^{9}$. Essa decisão pode ser influenciada, por exemplo, por (i) pressões políticas de atores ou movimentos sociais locais (inclusive partidos); (ii) tamanho e localização do município; e/ou (iii) capacidade fiscal da prefeitura.

Figura 2 | Distribuição espacial de elementos selecionados das capacidades estatais municipais
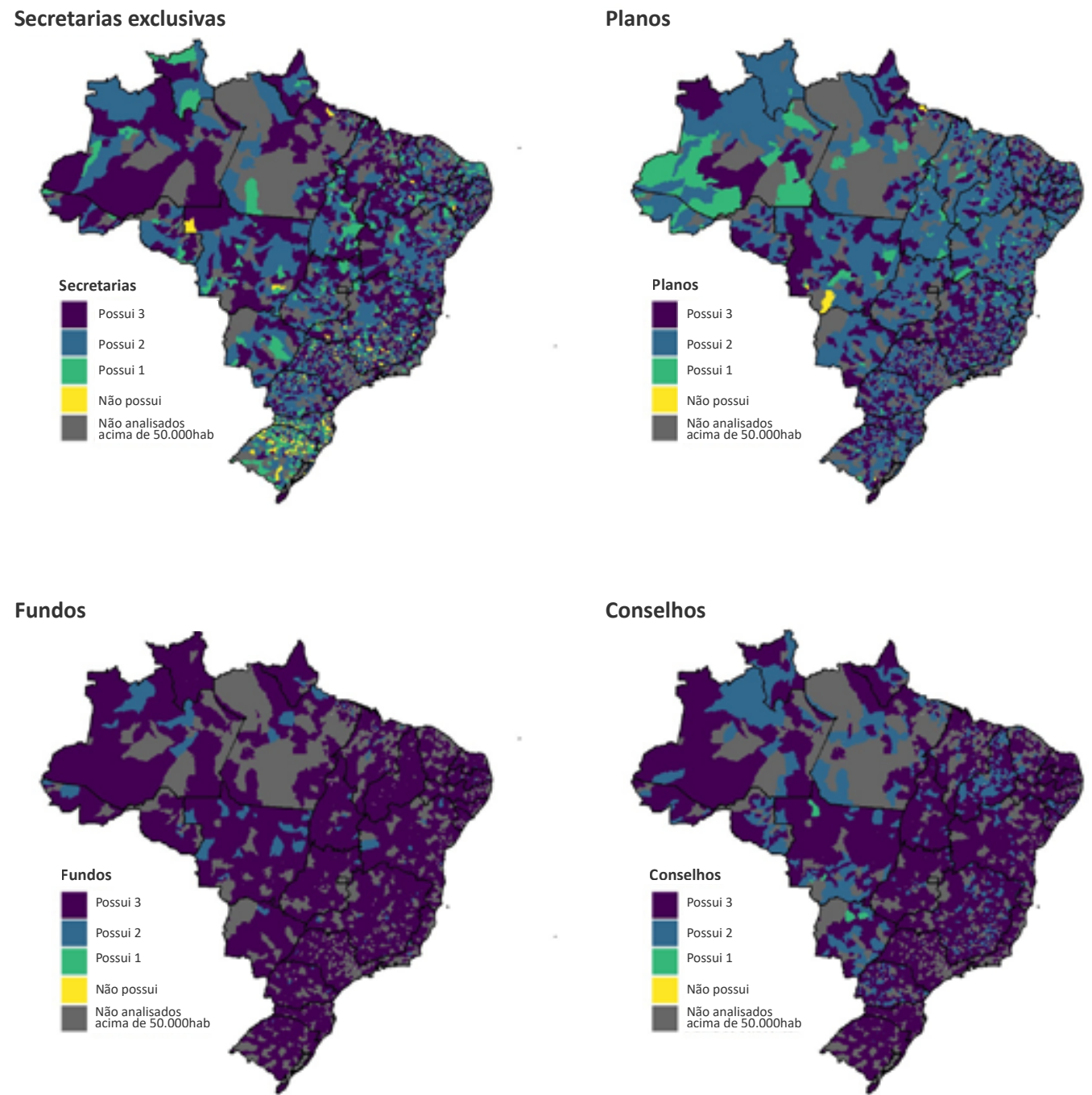

Fonte: Elaboração própria a partir de Munics 2013-2015.

\footnotetext{
${ }^{9}$ Embora a autora estivesse tratando exclusivamente de secretarias municipais de habitação, não há motivos para acreditar que os mesmos fatores não influenciem a existência de secretarias de outras áreas.
} 
Por fim, os resultados indicam ainda que a associação entre o percentual de burocratas profissionais (concursados com nível superior) na administração direta e o IDH-M, embora significante, é baixa e tende à nulidade. Esse resultado difere de outros estudos sobre capacidades estatais como Evans e Rauch (1999) e Marenco, Strohschoen e Joner (2017), que enfatizam a relação positiva entre burocracias profissionais e variáveis como o crescimento econômico e a arrecadação de IPTU. Deve-se lembrar, contudo, que diferentes formas de medir burocracia, bem como a análise de sua influência sobre diferentes variáveis de interesse (no nosso caso, o IDH-M), podem levar a diferentes conclusões. Há pelo menos dois fatores que podem contribuir para possíveis divergências. Primeiro, é possível que a relação entre burocracia e IDH-M varie de acordo com o tamanho do município. Marenco, Strohschoen e Joner (2017), Batista (2015) e Grin et al. (2018), por exemplo, trabalham com todos os municípios brasileiros com dados disponíveis, enquanto o presente estudo analisa apenas municípios com até 50 mil habitantes. É preciso avaliar nos modelos como as grandes cidades (como São Paulo e Rio de Janeiro, respectivamente com 12 e 6 milhões de habitantes) influenciam nos resultados. Segundo, a relação entre a burocracia profissional e o IDH-M pode ser não linear. Toral (2019), ao avaliar a performance de diretores escolares, afirma que, em governos com baixos níveis de capacidade, funcionários indicados politicamente (logo, sem a estabilidade profissional típica do modelo weberiano) tendem a atuar melhor do que aqueles selecionados por meio de processos meritocráticos, como concursos públicos. A explicação é que, nesses casos, a relação de confiança com o incumbente gera mais resultados do que a autonomia burocrática. Pesquisas futuras sobre a influência de burocracias profissionais na gestão de governos locais podem ajudar a esclarecer melhor esses pontos.

Do conjunto do exposto extrai-se que os componentes do modelo que engloba nossa definição de capacidades estatais municipais que estão mais fortemente associados aos mais altos níveis de desenvolvimento humano municipal são aqueles relacionados às atividades de interação e participação social: planejamento, formação de parcerias e participação através de conselhos. Aliás, dois desses elementos estão diretamente associados à dimensão político-relacional das capacidades estatais municipais. 


\section{Considerações Finais}

O estudo procurou analisar as relações entre capacidades estatais municipais e o índice de desenvolvimento humano local no Brasil. Nesta análise exploratória, trabalhamos com 4.916 municípios de pequeno porte, isto é, com menos de 50 mil habitantes. Para mensurar o desenvolvimento humano utilizamos o IDH-M, calculado por meio da agregação de indicadores de longevidade, educação e renda. Por capacidades estatais municipais entendeu-se a habilidade do governo local de planejar, implementar e manter de forma eficiente políticas sociais, em um processo que envolve múltiplos atores e interesses e muitas vezes é condicionado por indução federal. Adaptando os termos da literatura brasileira (PIRES; GOMIDE, 2014; GoMIDE; PEREIRA; MACHADO, 2017), tais capacidades são concebidas em duas dimensões: técnico-administrativa e políticorelacional. Pelos resultados encontrados, a disponibilidade de canais de participação, os arranjos institucionais e os instrumentos de planejamento e gestão estão associados às categorias de IDH-M mais elevado. Ou seja, os nossos resultados indicam que a participação de atores da sociedade civil na gestão municipal, as parcerias intra e intermunicipais e o ato de planejar estão fortemente associados a índices de IDH-M elevados.

Essa pesquisa, ainda incipiente, pretende ter vários desdobramentos futuros. O mais evidente é identificar a direção da causalidade: se a existência de conselhos e consórcios gera maior desenvolvimento humano ou se contextos marcados por níveis mais elevados de IDH-M aumentam oportunidades para a participação. Outra possibilidade é a ampliação do escopo da pesquisa. Dado que o IDH-M retrata as dimensões de saúde, educação e renda, outras políticas públicas devem ser observadas em pesquisas futuras (por exemplo, fazenda, desenvolvimento econômico e trabalho). Seria interessante também observar o que acontece em municípios com mais de 50.000 habitantes, assim como diferenças entre pequenos e grandes municípios. Finalmente, há a possibilidade de aprofundar o debate entre a literatura sobre capacidades estatais subnacionais e a literatura sobre descentralização e políticas públicas. Quanto à descentralização, se, por um lado, a produção de tais políticas tem sido alcançada por um arranjo de indução federal (ARRETCHE, 2012), por outro, como visto, as capacidades de gestão municipal importam para os resultados em termos dos níveis do desenvolvimento humano. Quanto às políticas 
públicas, ao tratar das capacidades dos entes locais no Brasil, é indispensável atentar ao papel dos "burocratas de nível de rua", que são responsáveis por entregar os bens, serviços e benefícios na ponta do processo aos beneficiários das políticas, que as recebem a partir de seu local de moradia (LIPSKY, 1980), e ao "poder discricionário" exercido por eles. Como sugere Lotta (2010, p. 249), esse "é um fator decisivo na distribuição de bens e serviços públicos; portanto, a ação desses agentes é uma variável relevante para o sucesso das políticas". Também Oliveira (2012, p. 1569) sugere que "o poder discricionário dos operadores que atuam nos guichês, nas enfermarias, nas salas de aula e nas ruas é decisivo na execução das políticas públicas". Esses aspectos precisam ser melhor aprofundados e incorporados ao modelo.

Entretanto, por si próprios os resultados aqui reportados têm grandes implicações não só para a compreensão do desenvolvimento humano brasileiro em geral, mas também do desenvolvimento político e administrativo da nação. Por um lado, os nossos resultados reforçam a tendência encontrada na literatura do 'Brasil participativo': da importância dos conselhos participativos, da participação pública e da concertação social entre os vários atores da sociedade brasileira como fatores propulsores das 'esferas públicas' de Habermas - espaços onde a sociedade engaja em um debate público crítico -, peças fundamentais para ação, deliberação e consolidação democrática. Por outro lado, de um ponto de vista gerencial, parece que a eficiência da gestão pública em nível municipal está relacionada com a capacidade local de planejar com outros: ou criando espaços participativos, ou coordenando a cooperação entre municípios e entre municípios e atores não estatais (sociedade civil e mercado). Ou seja, há uma necessidade de fomentar e cimentar esses espaços participativos e de interação para a consolidação democrática brasileira.

Num Estado moderno, as diferentes formas de capacidade estatal são frequentemente codependentes (BERWICK; CHRISTIA, 2018). Para isso, há uma necessidade de investir na formação de capacidade estatal municipal não apenas em recursos humanos, tecnológicos e estruturas de gestão, mas também em competências e atitudes para coordenação, concertação e planejamento conjunto. No entanto, o que tem se visto no período mais recente é o contrário disso. Sob o recente governo, as instituições participativas no Governo Federal têm sido extintas ou limitadas, tanto em seu escopo de atuação como em sua composição (por exemplo, por meio da retirada do direito de atores da sociedade civil participarem de determinados conselhos). O que se dá no plano federal 
tem desdobramentos no plano local. Um efeito cascata em pelo menos duas direções: desincentivos à mobilização por parte dos atores sociais e à manutenção dos espaços por parte dos agentes públicos. Em um contexto refratário e hostil, aumentam-se os custos da participação e, indiretamente, diminuem-se as capacidades governamentais locais.

\section{Referências Bibliográficas}

ARRETCHe, M. Trajetórias das desigualdades: como o Brasil mudou nos últimos cinquenta anos. São Paulo: Editora Unesp, 2015.

AgUIAR, Rafael Barbosa de; LIMA, Luciana Leite. Capacidade estatal: definições, dimensões e mensuração. BIB: Revista Brasileira de Informação Bibliográfica em Ciências Sociais. São Paulo, SP. N. 89 (ago. 2019), p. 1-28, 2019.

ARretche, M. T. da S. Capacidades administrativas dos municípios brasileiros para a política habitacional. 2012.

ArRetche, Marta; Vazquez, Daniel; Gomes, Sandra. Descentralização e autonomia: deslocando os termos do debate. O Horizonte da política-Questões emergentes e agendas de pesquisa. São Paulo: UNESP, p. 29-62, 2012.

AthiAS, L. et al. Indicadores de governança municipal, estadual e distrital no Brasil com dados da Munic (2005/2017) e da Estadic (2012/2017). In: ATHIAS, L.; BOTELHO, L. (Eds.). Panorama nacional e internacional da produção de indicadores sociais: estatísticas de governança. Estudos e análises. Informação demográfica e socioeconômica. Rio de Janeiro: IBGE, 2019.

BATISTA, M. Burocracia local e qualidade da implementação de políticas descentralizadas: uma análise da gestão de recursos federais pelos municípios brasileiros. Revista do Serviço Público, v. 66, p. 345-370, 2015.

BERSCH, K.; PRAÇA, S.; TAYLOR, M. State capacity and bureaucratic autonomy within national states: mapping the archipelago of excellence in Brazil. In: TRABAJO PRESENTADO EN LA LATIN AMERICAN StUdies Association CONFERENCE. Washington, D.C: 2013.

BERSCH, K.; PRAÇA, S.; TAYLOR, M. M. State capacity, bureaucratic politicization, and corruption in the Brazilian State: state capacity, bureaucratic politicization, and corruption. Governance, v. 30, n. 1, p. 105-124, jan. 2017.

BERWICK, E.; CHRISTIA, F. State capacity redux: integrating classical and experimental contributions to an enduring debate. Annual Review of Political Science, v. 21, p. 71-91, 2018. 
BRAUtigam, D. State capacity and effective governance. Agenda for Africa's economic renewal, v. 1996, p. 81-108, 1996.

BRASIL, AtLAS. AtLas do desenVolvimento humano no BRASIL, 2013. Disponível em: <htTP:// WWW.ATLASBRASIL.ORG.BR/>. ACESSO EM: 20 OUT. 2019.

Centeno, M. A. et al. States in the developing world. [s.I.] Cambridge University Press, 2017.

CINGOLANI, L. The state of State capacity: a review of concepts, evidence and measures. Maastricht: UNU-MERIT, Working Paper n.53, p.58, 2013.

CoElHo, R. et al. A participação conselhista no Brasil - uma proposta de análise por meio do índice de potencial participativo dos conselhos nos municípios (IPPC). In: ANAIS DO IV ENCONTRO internacional Participação, Democracia e Políticas Públicas. Porto Alegre, 2019.

CORTES, S. M. V. As diferentes instituições participativas existentes nos municípios brasileiros. In: PIRES, R. (Ed.). Efetividade das instituições participativas no Brasil: estratégias de avaliação. Brasília: Ipea, 2011.

CUNHA, R. E. da. Federalismo e relações intergovernamentais: os consórcios públicos como instrumento de cooperação federativa. Revista do Serviço Público, [S. I.], n.55, n.3 p. 5-36, 2004.

DEROUEN JR, K. et al. Civil war peace agreement implementation and state capacity. Journal of Peace Research, v. 47, n. 3, p. 333-346, 2010.

EDIGHEJI, O. Constructing a democratic developmental state in South Africa: potentials and challenges. In: EDIGHEJI, O. Constructing a democratic developmental state in South Africa. Cape Town: Human Sciences Research Council, 2010. p. 1-33

Escola Nacional de Administração Pública (EnaP), E. N. DE A. P. Capacidades estatais para produção de políticas públicas. Brasília: Enap, 2018a.

Escola nacional de AdMinistração Pública (ENAP). Desafios e condicionantes para a implementação da Agenda ODS na administração pública federal. Brasília: Enap, 2018b.

Evans, P. B. Embedded Autonomy: States and Industrial Transformation. Princeton: Princeton University Press, 1995.

EVANS, P.; RAUCH, J. E. Bureaucracy and growth: a cross-national analysis of the effects of "Weberian" State structures on economic growth. American Sociological Review, v. 64, n. 5, p. 748-765, 1999.

FUKUYAMA, F. What is governance? Governance, v. 26, n. 3, p. 347-368, 1 jul. 2013.

GALVÃo, Juliana de Castro; SOARES, Andrei Suárez Dillon. A participação sob medida: a existência e os graus de atividade de conselhos de direitos enquanto determinantes das políticas municipais para pessoas com deficiência. In.: Anais do III Encontro Internacional Participação, Democracia e Políticas Públicas, UFES, Vitoria-ES, 2017.

Gomide, A.; Pereira, A. K.; MACHAdo, R. Apresentação - O conceito de capacidade estatal e a pesquisa científica. Sociedade e Cultura, v. 20, n. 1, 27 dez. 2017. 
GomIDE, A.; PIRES, R. Capacidades estatais e democracia: a abordagem dos arranjos institucionais para análise de políticas públicas. In: GOMIDE, A.; PIRES, R. (Eds.). Capacidades estatais e democracia: arranjos institucionais de políticas públicas. Brasília: Ipea, 2014. p. 15.

GRIN, E. J. et al. Sobre desconexões e hiatos: uma análise de capacidades estatais e finanças públicas em municípios brasileiros (About disconnections and gaps: an analysis of state capacity and public finances in brazilian municipalities). Cadernos Gestão Pública e Cidadania, São Paulo, v. 23, n. 76, p. 312-336. dez. 2018.

HANSON, J. K.; SIGMAN, R. Leviathan's latent dimensions: measuring state capacity for comparative political research. In APSA 2011 Annual meeting paper. 1 set. 2013.

HELLER, P. Towards a sociological perspective on democratization in the global south: lessons from Brazil, India and South Africa. In: COMPARATIVE RESEARCH WORKSHOP, Yale University. 2011.

INSTITUTO Pólis. O estado das cidades no Brasil. RELATÓRIO 2000-2009. 2013. Disponível em: <https://www.polis.org.br/uploads/1779/1779.pdf>. Acesso em: 20 out. 2019.

JANNUZZI, P. DE M. Indicadores nos ciclos de políticas públicas e programas sociais no Brasil. In: REIS, A. C. A. dos; SIMÕES, A. (Eds.). Indicadores sociais: passado, presente e futuro. Brasília: IBGE, 2017.

Lavalle, A. G.; Barone, L. Conselhos, associações e desigualdade. In: Arretche, M. T. da S. (Ed.). Trajetórias das desigualdades: como o Brasil mudou nos últimos cinquenta anos. São Paulo: Editora UNESP, 2015.

LINDVALL, J.; TEORELL, J. State capacity as power: a conceptual framework. [s.I.] Department of Political Science, Lund University, 2016.

LIPSKY, Michael. Street-level bureaucracy: dilemmas of the individual in public services. Nova York: Russel Sage Foundation, 1980.

LOTTA, G. S.; VAZ, J. C. Arranjos institucionais de políticas públicas: aprendizados a partir de casos de arranjos institucionais complexos no Brasil. Revista do Serviço Público, [S. I.], 66, n.2, p. 171194, 2015. Disponível em: <https://revista.enap.gov.br/index.php/ RSP/article/view/409>. Acesso em: 20 out. 2019.

LOTTA, Gabriela Spanghero. Implementação de políticas públicas: o impacto dos fatores relacionais e organizacionais sobre a atuação dos burocratas de nível de rua no Programa Saúde da Família. Tese de Doutorado. Universidade de São Paulo, 2010.

MANN, M. The autonomous power of the state: its origins, mechanisms and results. European Journal of Sociology / Archives Européennes de Sociologie / Europäisches Archiv für Soziologie, v. 25, n. 2, p. 185-213, 1984.

Marenco, A.; Strohschoen, M. T. B.; Joner, W. Capacidade estatal, burocracia e tributação nos municípios brasileiros. Revista de Sociologia e Política, v. 25, n. 64, p. 3-21, dez. 2017.

OliveirA, J. A. P. de. Desafios do planejamento em políticas públicas: diferentes visões e práticas. Revista de Administração Pública, v. 40, n. 2, p. 273-288, 2006. 
OliveirA, Antonio. Burocratas da linha de frente: executores e fazedores das políticas públicas. Revista de Administração Pública, 46(6), 1551-1573, 2012

PIRES, R.; GOMIDE, A. Análise comparativa: arranjos de implementação e resultados de políticas públicas. In: GOMIDE, A.; PIRES, R. (Eds.). Capacidades estatais e democracia: arranjos institucionais de políticas públicas. Brasília: Ipea, 2014. p. 351-379

PIRES, R. R. C.; GomIDE, A. de Á. Governança e capacidades estatais: uma análise comparativa de programas federais. Revista de Sociologia e Política, v. 24, n. 58, p. 121-143, jun. 2016.

RePETTO, F. Capacidad Estatal: requisito para el mejoramiento de la Política Social en América Latina. INDES Working paper series; I-52, 2004.

RiBEIRO, J. M.; COSTA, N. do R. Regionalização da assistência à saúde no Brasil: os consórcios municipais no Sistema Único de Saúde (SUS). Planejamento e Políticas Públicas, n. 22, p. 174-220, 2000.

SADEK, M. T. A. Poder local: perspectivas da nova ordem constitucional. São Paulo Perspect, p. 9-15, 1991.

SÁTYRO, N. G. D.; CUNHA, E. S. M.; CAMPOS, J. Análise espacial da burocracia da assistência social nos municípios brasileiros: notas para uma reflexão sobre a capacidade de implementação dessa política. Opinião Pública, v. 22, n. 2, p. 286-317, ago. 2016.

SKOCPOL, T. Bringing the State Back In: Strategies of Analysis in Current Research. In: EVANS, P. B.; RUESCHEMEYER, D.; SKOCPOL, T. (Eds.). Bringing the State Back In. Cambridge: Cambridge University Press, 1985. p. 3-38.

SouzA, C. Capacidades estatais para a promoção de processos participativos. Brasília: Universidade de Brasília, 2016.

SouzA, C. Federalismo e capacidades estatais: o papel do estado-membro na política de assistência social. In: Pires, R.; Lotta, G.; Oliveria, V.E. (Org.). Burocracia e políticas públicas no Brasil: inserções analíticas. Brasília : Ipea : Enap p.269-297, 2018.

SouzA, L. M. de; RodRIGUES, M.; SouzA SILVA, J. P. de. Institucionalização e capacidades estatais em dois municípios capixabas atingidos pelo desastre-crime do rio doce: os casos de Colatina e Linhares. Revista Psicologia Política, v. 19, n. 1, p. 84-103, 2019.

SPOSATI, A. DE O. et al. Mapa da exclusão/inclusão social da cidade de São Paulo. In: SPOSATI, A. DE O (Coord.). Mapa da exclusão/inclusão social da Cidade de São Paulo. São Paulo, EDUC, 1996.

Sposati, A. de O.; Toledo, J. R. de. Cidade em pedaços. In: SPOSATI, A. de O. Cidade em pedaços. [s.I.] Editora Brasiliense, 2001.

Tilly, C.; ARDANT, G. The formation of national states in Western Europe. Princeton, NY: Univ. Press, 1975.

TORAL, G. The Benefits of Patronage: How the Political Appointment of Bureaucrats Can Enhance Their Accountability and Effectiveness. Working paper. 1 out 2019. Disponível em: http://dx.doi. org/10.2139/ssrn.3462459. Acesso em: 20 out. 2019. 
Touchton, M.; Sugiyama, N. B.; WAMPleR, B. Democracy at Work: Moving Beyond Elections to Improve Well-Being. American Political Science Review, v. 111, n. 1, p. 68-82, fev. 2017.

Veloso, J. F. et al. Uma visão inicial dos subsistemas da gestão pública municipal. In: Veloso, J. F. et al. (Eds.). Gestão municipal no Brasil: um retrato das prefeituras. Brasília: Ipea, 2011. p. 11-40.

WILLIAMS, M. J. Beyond state capacity: Bureaucratic performance, policy implementation, and reform. [s.I.] Technical Report, Mimeo, 2018.

YEE, T. W. The VGAM package for categorical data analysis. Journal of Statistical Software, v. 32, n. 10, p. 1-34, 2010.

\section{Rony Coelho}

(iD https://orcid.org/0000-0002-3312-4021

Rony é cientista político e possui doutorado e mestrado na área pela Universidade Estadual de Campinas (Unicamp). Realizou estágio pós-doutoral pelo projeto "Procad - Participação política" (UFSC/UNESP/UEM), onde coordenou o desenvolvimento dos bancos de dados Munics-IPs e Estadics-IPs, e atuou como Visiting Research Fellow no Institute of Development Studies (IDS), Reino Unido (CAPES, processo: 88881.170110/2018-01). Atualmente trabalha como consultor independente.

E-mail: coelhorgs@yahoo.com.br

\section{Felipe Guth}

(iD) https://orcid.org/0000-0002-0932-1797

Felipe é consultor em políticas públicas na Technopolis. Anteriormente, trabalhou por vários anos como gerente de projetos no Banco Nacional de Desenvolvimento Econômico e Social (BNDES). Ele possui mestrado em Governança, Desenvolvimento e Políticas Públicas pelo Institute of Development Studies (IDS) da Universidade de Sussex e mestrado em economia pela Universidade Federal do Rio de Janeiro (UFRJ).

E-mail: feguth@gmail.com

\section{Miguel Loureiro}

(iD) https://orcid.org/0000-0001-6793-0649

Miguel Loureiro é pesquisador e diretor do mestrado em Governança, Desenvolvimento e Políticas Públicas do Institute of Development Studies (IDS) no Reino Unido. Como cientista social interdisciplinar, sua pesquisa se concentra principalmente na interação entre atores estatais e não estatais e na capacidade de resposta estatal.

E-mail: M.Loureiro@ids.ac.uk 